\title{
Diagnostic value of a psychological test in cases of suspected child abuse
}

\author{
DAVID C. GEDDIS,* IRENE F. TURNER, AND JANICE EARDLEY \\ From the Royal Belfast Hospital for Sick Children, and the Department of Psychology, Queen's University \\ of Belfast
}

SUMmaRY The use of the Bene-Anthony Family Relations Test is described, and illustrated by three examples of child abuse. This test should be considered in the investigation of definite or suspected cases of abuse and as part of the preparation of court evidence.

The term 'child abuse' no longer refers only to the 'battered child', the emotive term originally applied to infants and children who were victims of nonaccidental injury (Kempe et al., 1962), and the concept now includes children failing to thrive because of inadequate mothering (Babero and Shaheen, 1967; Schmitt and Kempe, 1974) or showing other signs of maternal deprivation or neglect (Rutter, 1972). Maternal deprivation or neglect commonly refers to material factors, with lack of adequate food, clothing, or shelter, but the phenomenon of emotional neglect, in which the caretaker provides insufficient warm, sensitive interaction for optimal growth and development, may be both more prevalent and more important. Often a patient may show evidence of both physical and emotional maltreatment (Steele, 1968): children may be brought to the attention of doctors after an episode of physical violence but, on detailed assessment, the physical aspect assumes relatively minor importance compared to the severity of emotional abuse. The attempt to isolate the various types of abuse is well recorded (Gibson, 1974).

The concept of emotional abuse is not readily amenable to scientific study and the doctor is in difficulty when asked to assess suspected cases of it. $\mathrm{He}$ is often called upon to co-operate closely with other professions in the preparation of court evidence, and Pringle (1974) advocates interdisciplinary evaluation.

We have experienced situations where deprivation was considered likely and the psychosocial environment was probably the predominant factor leading

Received 16 February 1977

*Present address: Department of Paediatrics and Child Health, University of Otago, Dunedin, New Zealand. to the child's presentation. Yet, because of lack of co-operation or insight on the part of parents, confirmatory evidence was difficult to obtain.

There is a wealth of literature providing guidance on the collection and interpretation of information (Pollock and Steele, 1972; Schneider et al., 1972; Hall, 1974). Since much of this deals with nonaccidental injury, most common in infants, it is not surprising that little attention has been directed towards obtaining the child's view of the situation. Obviously when the patient is very young such an approach is impossible and even with older children it is difficult. Our view that direct questioning seldom has much value is supported by a number of studies which have examined the relative usefulness of direct and indirect questioning, with or without pictures designed to elicit relevant responses (Kagan and Lemkin, 1960).

What follows is, in essence, an account of our experience in using the child's viewpoint to highlight problems deserving further investigation. Since the Family Relations Test (Bene and Anthony, 1957) had given evidence of validity in use with normal children (Turner, 1977), we hypothesized that unusual patterns of response might identify areas for exploration. To examine this hypothesis the test was used in situations where one of us was aware of relevant medical and other data but the tester and evaluator were not.

Three examples are reported. In 2 cases, where violent episodes precipitating admission had forced the parents to accept the seriousness of the problem and to seek help, the test was part of the investigative procedure. In the third case, it is apparent that earlier use of the test might have accelerated a satisfactory outcome. 


\section{Method and materials}

The Family Relations Test was devised to measure the emotional attitudes of the child to family members and his view of their feelings towards him (Bene and Anthony, 1957). Although the rationale of the test accords with psychoanalytic theory, its use has not been confined to any particular school of psychological thought and a number of studies have dealt with its validity and reliability (Meyer, 1963; Frost, 1969; Kauffman, 1970; Roche, 1970). Some reservations have been expressed about its suitability for adolescents, but it is highly regarded for use with younger children (Chazan, 1970). Our preference for the Family Relations Test may be seen in the context of our experience with other measures, such as the Pickford Projective Pictures (Pickford, 1963), the Family Relations Indicator (Howells and Lickorish, 1962), or the Jackson Test for Family Attitudes (Jackson, 1952). All three require speech, unlike the Family Relations Test where talking is not essential: statements are read aloud by the tester, though older children may read for themselves. A particular feature is the relative simplicity of the task, which permits its use with very young children. The test manual does not stipulate a minimum age for testing and much may depend upon intelligence and personality. We have used it successfully with children of average intelligence aged $\mathbf{4 2}$ months or older but it seems wise to interpret cautiously the responses of subjects aged less than $\mathbf{4 8}$ months.

The test material consists of 20 cardboard figures, ambiguously drawn, representing people of various ages, from grandparents to a baby in a pram, and with a posting box attached to each. The child is helped to select those which best represent himself and the members of his family. His choices may reflect his emotional life, rather than the nominal structure of his family; for example, he may exclude a parent or sib not resident in the home, or with whom he has little interaction, and include unrelated individuals who are resident or with whom he has frequent contact. An additional character, Mr. Nobody, is then added to the selected group.

There are two sets of cards, one designed for use with children up to 8 years old and a longer series for older children and adolescents. Each card carries a statement which may be read to, or by, the child. $\mathrm{He}$ is asked to 'post' the card into the box appropriate to the person whom it seems to fit best. If the child feels that the statement does not apply to any member of the family it is posted to Mr. Nobody. The statements are designed to represent positive and negative emotions, towards and from the child, as well as feelings of dependency.

The version for younger children contains 40 items. Once a card is 'posted' it is out of sight and it is highly improbable that the child will be conscious of the cumulative distribution of his allocations (Linton et al., 1961). The absence of a visible reminder, together with the possibility of assigning statements to Mr. Nobody, is intended to minimize feelings of guilt or anxiety, while encouraging freedom of expression (Bene and Anthony, 1957).

The relative importance for the child of the various family members is reflected in the numbers of items allocated to each. Bene and Anthony (1957) suggest that normally the distribution of responses should be: mother, father, sibs, and others in descending order of emotional involvement. Furthermore, there should be evidence of belief that others reciprocate the feelings which he holds towards them. Empirical support for these hypotheses is provided by Linton et al. (1961) and Turner (1977).

Patently, the validity of such a test is called in question in any case where there is an element of doubt about the subject's ability to comprehend the oral instructions. In each instance, therefore, the child was pretested, using the English Picture Vocabulary Test to assess his listening vocabulary, and only those who achieved raw scores in the normal range for $4 \frac{1}{2}$-year-olds (or higher) were given the Family Relations Test.

\section{Results}

Case 1. A male, aged 4 years 10 months. Presenting symptoms: encopresis; possible mental retardation.

Family Relations Test. His ordering was: mother, father, sibs, grandparents, and self. Examination of the incoming and outgoing feelings expressed in relation to father, sibs, grandparents, and self showed the expected, balanced pattern and the distribution closely approximated the mean values normally obtained with children in this age group (Turner, 1977). The contrast between these responses and the magnitude and form of the emotional involvement with the mother, as indicated by the test, was particularly striking: he assigned twice the usual number of cards to his mother and slightly more than two-thirds of these items reflected negative emotions. This suggested the existence of a distorted relationship, involving hostility, which required further investigation. (Remarks volunteered by Case 1, during testing, referred to violent acts towards him on the part of his mother.)

Paediatric details. After a severe beating administered by his mother, this child was referred by his general practitioner to the social services. He was admitted to hospital for investigation of encopresis 
and possible mental retardation. Interviews with the parents disclosed an abnormal situation exacerbated, but not caused, by his encopresis. During her pregnancy, relations between his mother and her mother-in-law had been strained because the latter had cast doubt upon the paternity of the expected child. Case 1 was born 6 weeks preterm and suffered severe respiratory distress. His mother expected him to die and, when he eventually came home, was afraid to handle him. She was severely depressed for 6 months and the child was not fully accepted by the in-laws.

His father was holding down three jobs, which left little time for participation in the life of the family. Some months previously the maternal grandfather had been diagnosed as having terminal cancer and this further reduced the mother's ability to cope.

After the results of the Family Relations Test, further interviews with the parents were arranged. Both admitted that the mother had always been hard on the child, but asserted that she began to lose control only after the diagnosis of her father's illness. Skeletal $x$-rays showed evidence of previous 'accidents' and, during his stay in hospital, the child soiled only when his mother came to visit him.

In this case the usefulness of the Family Relations Test is apparent, focusing attention on the motherchild relationship which was a major causative factor in the encopresis. Other psychological tests ruled out mental retardation.

Case 2. Female, aged 9 years 9 months. Presenting symptoms: failure to thrive; short stature.

Family Relations Test. Her ordering was: sibs, mother, father, self, and grandmother. Twice as many responses were assigned to her sibs as to her mother, suggesting a distorted pattern of family dynamics and providing some evidence of displacement of emotional involvement from the central, parental figures. There were marked discrepancies between her feelings, both positive and negative, expressed towards her mother, and her mother's feelings, as perceived, towards herself. Outgoing negative responses to the mother were few and no incoming negative responses were given. The unreality of this pattern may be gauged by comparison with the corresponding responses in relation to sibs, where the usual balanced distribution was found: outgoing negative responses towards her sibs corresponded with her perception of incoming negative feelings from them.

The pattern of responses was unusual, indeed extreme, and merited further investigation to explore the possibility of serious disturbance in the child and/or in the psychodynamics of the family.
Paediatric details. It is of interest that when this child, as an inpatient, was investigated for short stature at the age of 4 and again as an 8-year-old, the parents did not mention having any unusual difficulties with her. She was thoroughly investigated and, with the exception of a delayed bone age, all the results were within the normal range.

On the most recent occasion, she was admitted to hospital after being severely beaten by her mother. This followed a school report of pilfering food from refuse receptacles and from other children's luncheons. By this stage there were sufficient pointers to warrant further exploration of the family relationships. From the parents it was learned that she had been born 8 weeks preterm and remained in hospital for 3 months. The mother was pleased to have a girl but feared that she would not survive. When she came home she was thought not to resemble anyone in the family and was regarded as a 'hospital baby'.

The child's father felt that his wife never wanted the child and that she required her to work unduly hard in the house. The general practitioner stated that, the previous Christmas, the sibs, one aged 11 and the other 8 , had received expensive presents while Case 2 was given a cheap doll, later appropriated by her sister.

Results of the Family Relations Test led to further interviews with the mother and discussion of her relationship with the child. She volunteered that she had feelings of guilt because of her initial reactions to the child which she believed to be the source of the child's abnormal behaviour. Further, she admitted punishing the child because the abnormal behaviour increased her personal sense of guilt.

Case 3. Male, aged 6 years 3 months. Presenting symptoms: suspected mental retardation.

Family Relations Test. His ordering was: father, mother, sibs, self, and grandmother, and he assigned an exceptionally large number of cards to Mr. Nobody. Bene and Anthony (1957) describe this as a denial tendency, the child opting out of potentially painful allocations. Hyman and Mitchell (1975), who investigated a sample of 'battered' children, found that they showed a significantly greater involvement with the father than did controls and that they allocated significantly more cards to Mr. Nobody. However, in this child's distribution the difference between the numbers of items assigned to the 2 parents was small and his attitude towards his mother showed no ambivalence. (Ambivalence towards a family member is indicated if neither the number of positive items nor the number of negative items exceeds two-thirds of their combined number.) Similarly, his general pattern of incoming and out- 
going feelings to sibs was balanced and within the normal range.

His choice of items for his grandmother showed three interesting aspects: (1) he assigned her fewest cards, indicating a very low involvement; (2) he included no positive emotions towards her; (3) his allocation of incoming emotions from her revealed ambivalence. This pattern, together with the excessive use of Mr. Nobody, suggested that more information should be sought in relation to the attitudes and behaviour of his grandmother.

Paediatric details. This boy, the second of 3 children, was first seen as a hospital outpatient at the age of 14 months. His mother considered that he was eating and crying excessively but physical examination showed a normal infant, not overweight. At the age of 3 he was again seen as an outpatient: his grandmother believed he was masturbating and had difficulty in accepting that his observed behaviour was due to a paraphimosis.

When $4 \frac{1}{2}$ years he was presented in a neglected, undernourished condition. Both height and weight were below the 3rd centile. He was not walking. He had bruises of varying ages to different parts of his body and was incontinent of urine and faeces. Though he spoke only a few words, the impression of the ward staff was that he understood what was being said.

It will be noted that a variety of circumstances led to his various presentations. His is a case in which, regrettably, the Family Relations Test was not included as a part of a general investigative procedure. However, investigation by the social services showed that he was largely ignored by his parents, both of whom were working. He was looked after by his grandmother who constantly denigrated the child, punished him physically for his incontinence, and generally used excessive violence towards him for trivial reasons.

The outcome of this case is instructive. Central to it is the removal of the child from his home environment. In view of his apparent severe mental and physical retardation, he was admitted to a diagnostic centre for mentally handicapped children. Various investigations were carried out with regard to his failure to thrive and all the results were normal, with the exception of bone age which was 15 months (chronological age $4 \frac{1}{2}$ years). As an inpatient he made dramatic progress physically and intellectually and after 18 months he was found to be just below the 50th centile for height and weight. His speech had improved and he was making educational progress consonant with his measured intelligence (Stanford-Binet IQ 86: chronological age 64 years). The Family Relations Test formed part of this assessment and the accuracy with which the test, even when employed post-hoc, reflected highly significant features of the social-emotional climate of the home suggests that its earlier use might have hastened the action which was so clearly in the interests of the child.

\section{Discussion}

Formulation of satisfactory management plans demands understanding of many factors associated with individual cases of child abuse. In instances when it seems in the child's best interest to suggest that he be removed from his current environment, doctors discover that, in court, the definition of child abuse and neglect is not what the doctor thinks it should be, or what the social worker thinks it is, but is actually what the court says it is (Kempe, 1973). A case is strengthened by medical evidence of non accidental injury (Cavenagh, 1975) but to persuade the court, in the absence of such injury, that the child's presentation may be related to a detrimental environment can be a very difficult task. We suggest that in the overall preparation of such a case the child's reaction to his family environment, as expressed through the Family Relations Test, be included.

Apart from its application in instances of definite emotional abuse, there is a case for using the test with children who present to the paediatrician with one or more of the associated symptoms, e.g. poor language development, general development delay, short stature, or behaviour problems (Rutter, 1972). There are probably many children such as Case 2 in whom a nonphysical cause for the presenting symptoms is suspected only when exhaustive laboratory tests have produced negative results. A full psychosocial history should be part of the documentation of all paediatric patients but there are instances when accurate data are not forthcoming from the parents. In such cases, the Family Relations Test does not provide the answers but it can alert the paediatrician to significant questions. Just as in general medicine it is essential to view the result of any special investigation in the light of all available clinical information, so the information given by the Family Relations Test is of greatest value when used in conjunction with all other sources of information about the child and his family.

\section{References}

Babero, G. J., and Shaheen, E. (1967). Environmental failure-to-thrive: a clinical view. Journal of Pediatrics, 71, 639-641.

Bene, E., and Anthony, E. J. (1957). Manual for the Family Relations Test. National Foundation for Educational Research in England and Wales, Slough. 
Cavenagh, W. (1975). Battered children cases in the courts. Concerning Child Abuse, p. 140. Ed. by A. W. Franklin. Churchill Livingstone, Edinburgh and London.

Chazan, M. (1970). Maladjusted children. The Psychological Assessment of Mental and Physical Handicap, Chapter 18. Ed. by P. Mittler. Methuen, London.

Frost, B. P. (1969). The family relations test: a normative study. Journal of Projective Techniques and Personality Assessment, 34, 409-413.

Gibson, J. (1974). Parental abuse of children. Social Work Today, 5, 51-54.

Hall, M. H. (1974). The diagnosis and early management of nonaccidental injuries in children. Police Surgeon, Oct. 17.

Howells, J. G., and Lickorish, J. R. (1962). Manual for the Family Relations Indicator. National Foundation for Educational Research in England and Wales, Slough.

Hyman, C. A., and Mitchell, R. (1975). A psychological study of child battering. Health Visitor, 48, 294-296.

Jackson, L. (1952). A Test of Family Attitudes. Methuen, London.

Kagan, J., and Lemkin, J. (1960). The child's differential perception of parental attributes. Journal of Abnormal and Social Psychology, 61, 440-470.

Kauffman, J. M. (1970). Validity of the family relations test: a review of research. Journal of Projective Techniques and Personality Assessment, 34, 186-189.

Kempe, C. H. (1973). A practical approach to the protection of the abused child and rehabilitation of the abusing parent. Pediatrics, 51, 804-812.

Kempe, C. H., Silverman, F. N., Steele, B. F., Droegemueller, W., and Silver, H. K. (1962). The battered-child syndrome. Journal of the American Medical Association, 181, 17-24.

Linton, H., Berle, B. B., Grossi, M., and Jackson, E. (1961). Reactions of children within family groups as measured by the Bene-Anthony tests. Journal of Mental Science, 107, 308-325.
Meyer, M. M. (1963). Family relations test. Journal of Projective Techniques and Personality Assessment, 27, 309-314.

Pickford, R. W. (1963). Pickford Projective Pictures. Tavistock Publications, London

Pollock, C., and Steele, B. (1972). A therapeutic approach to the parents. Helping the Battered Child and His Family, p. 3. Ed. by C. H. Kempe and R. E. Helfer. Lippincott, Philadelphia.

Pringle, M. L. K. (1974). Identifying deprived children. Proceedings of the Royal Society of Medicine, 67, 10611062.

Roche, D. J. (1970). The Bene-Anthony family relations test: variations and reliability of administration procedure. Papers in Psychology, 4, 12-15.

Rutter, M. (1972). Maternal Deprivation Reassessed. Penguin, Harmondsworth.

Schmitt, B. D., and Kempe, C. H. (1974). The battered child syndrome. Brennemann's Practice of Pediatrics, Vol. 1, Chap. 22. Ed. by V. C. Kelley. Harper and Row, Maryland.

Schneider, C., Pollock, C., and Helfer, R. E. (1972). Interviewing the parents. Helping the Battered Child and His Family, p. 55. Ed. by C. H. Kempe and R. E. Helfer. Lippincott, Philadelphia.

Steele, B. F. (1968). Paper given at Annual Council Meeting of the NSPCC on The Battered Child, p. 14.

Turner, I. F. (1977) Pre-school Playgroups Research and Evaluation Project. Final report to Northern Ireland Department of Health and Social Services. HMSO, Belfast.

Correspondence to Dr. I. F. Turner, Department of Psychology, The Queen's University of Belfast, Belfast BT7 1NN, Northern Ireland. 